\title{
PYROLYSIS OF ACTIVATED CARBONS EXHAUSTED WITH ORGANIC COMPOUNDS
}

\author{
C.O. Ania, J.B. Parra, C. Pevida, A. Arenillas, F. Rubiera, J.J. Pis \\ Instituto Nacional del Carbón, C.S.I.C., Apartado 73, 33080, Oviedo, Spain.
}

\begin{abstract}
The regeneration of activated carbons used for the decontamination of water and wastewater polluted with organic compounds related to the pharmaceutical industry, has been studied in this work. To this end, the pyrolysis of exhausted activated carbons was performed in a quartz reactor. The influence of the pyrolysis of saturated activated carbons on their adsorptive capacities and porous structure was evaluated. Textural characterisation of the samples was carried out by helium density, and $\mathrm{N}_{2}$ and $\mathrm{CO}_{2}$ adsorption isotherms, at -196 and $0{ }^{\circ} \mathrm{C}$, respectively. Consecutive cycles of pyrolysis of activated carbons exhausted with phenol and salicylic acid, generated a widening of the microporosity, and a decrease in the apparent BET surface areas. The adsorptive capacities for phenol retention after a series of adsorption/pyrolysis cycles were found to decrease drastically. In contrast, consecutive cycles gave higher salicylic acid adsorptive capacities, as compared to phenol. The DTG pyrolysis profiles of the samples saturated with salicylic acid appeared at lower temperatures than those of phenol, which showed two peaks, while those exhausted with salicylic acid only showed one. These results provide evidence of the different adsorption mechanisms of these two pollutants.
\end{abstract}

Keywords: activated carbon, pyrolysis, liquid adsorption, porosity, surface area

\section{INTRODUCTION}

Until now, the active ingredients of pharmaceutical products have received little attention from the scientific community in spite of their extensive use all over the world. Growing concern is now emerging due to the presence of pharmaceutical residues in water and wastewater. This is understandable given the risk they pose to the environment and to human health [1]. Interest has been mainly focused on veterinary antibiotics but recent studies also report the presence of residues of human pharmaceuticals in wastewater and the aquatic environment. Information on the environmental hazard of the majority of pharmaceuticals is scarce, and hence, the possible adverse impact of these residues is uncertain.

Activated carbons (AC) are widely used for decontamination processes such as the purification of drinking water [2], wastewater treatment [3,4], and emissions control [5], as harmful pollutants present a high affinity for the porous surface of carbonaceous adsorbents [6-8]. In the processing of chemicals, pharmaceuticals and their intermediates, AC are also used for purification and recovery [9]. The treatment of the polluted effluents with AC prevents the deposition of contaminants and enables valuable products to be recycled to the manufacturing process. Treatment of industrial wastewater is 
increasing in industrialising countries and so the need to reuse water and reduce effluent pollution is greater.

The adsorption capacity of a given AC depends on several factors including its textural and chemical structure. However, despite its high surface area, it becomes saturated after sustained use. Formerly, when an AC reached its saturation limit, it was simply discarded, generating a secondary source of pollution. However, the spent AC has to be considered a hazardous waste in itself, and so it requires special treatment. The increasing concern regarding the effect of pollutants on the environment, along with the more restrictive environmental regulations introduced in recent years has motivated companies to develop methods for regenerating and reusing saturated activated carbon. The regeneration of AC is crucial for ensuring that the adsorption process becomes economically attractive [10]. Over the years, a variety of regeneration techniques have been applied [11-14]. The most extensively used technique is thermal regeneration. Steam or an inert atmosphere are sometimes used to destroy organic contaminants and recycle the carbon for reuse.

Although much effort has already been directed towards methods of regenerating AC [11-17] the role of the nature of the adsorbate and the characteristics of the adsorbent in the desorption process still need to be elucidated. The aim of this work was to study the effect of the pyrolysis of saturated AC on their adsorptive capacities for the retention of organic compounds related to the pharmaceutical industry and on the porous structure of the AC. The object chosen for this study was a high-volume pharmaceutical common metabolite: salicylic acid, which is the primary hydrolytic metabolite of acetylsalicylic acid. The removal of phenol was also investigated and compared to that of salicylic acid, as both of these products are present in wastewater as a consequence of the industrial production of a common analgesic. This information will be useful for future applications of AC in industrial processes and in the area of the thermal desorption of phenol and related compounds.

\section{EXPERIMENTAL}

$\mathrm{Q}$ is a commercial AC obtained by physical coal activation with steam. The as-received sample was ground and a particle size fraction of 0.075-0.212 mm was used for the studies. Prior to use, the carbon was washed several times with deionised water. Afterwards it was dried in an oven at $110{ }^{\circ} \mathrm{C}$ for 2 days and stored in a desiccator until used.

Textural characterisation was carried out by measuring helium density, and $\mathrm{N}_{2}$ and $\mathrm{CO}_{2}$ adsorption isotherms, at -196 and $0{ }^{\circ} \mathrm{C}$, respectively, in an automatic apparatus (Micromeritics ASAP $2010 \mathrm{M}$ ). The surface areas and microporosity were calculated from the physical adsorption of $\mathrm{N}_{2}$ using the BET and the Dubinin-Radushkevich equations, respectively [18]. The distribution of pores smaller than $0.7 \mathrm{~nm}$ (narrow microporosity) was assessed from $\mathrm{CO}_{2}$ adsorption at $0{ }^{\circ} \mathrm{C}[19]$.

Rapid small-scale column tests (RSSCT) were used as a feasible and less time-consuming procedure for the evaluation of the adsorptive capacity of pollutants [20]. The tests were performed at $30^{\circ} \mathrm{C}$. Breakthrough curves were obtained using $10 \mathrm{~cm}$ length stainless steel columns with an internal 
diameter of $1.5 \mathrm{~cm}$, packed with $5 \mathrm{~g}$ of AC. All the experiments were conducted with an initial concentration of $2 \mathrm{~g} \mathrm{l}^{-1}$ of pollutant, at a flow rate of $4 \mathrm{ml} / \mathrm{min}$. After the columns had been loaded, the carbons were soaked in deionised water for 2 hours. The outlet concentration was continuously monitored by a UV-VIS spectrophotometer set to the corresponding wavelength. The adsorptive capacities were obtained by integrating over the entire breakthrough curve.

After the saturation limit was reached, the exhausted AC were washed with distilled water for 2 hours, and dried overnight in an oven at $110^{\circ} \mathrm{C}$. Afterwards, they were pyrolysed in a quartz reactor at $850{ }^{\circ} \mathrm{C}$, under a nitrogen flow rate of $10 \mathrm{ml} \mathrm{min}^{-1}$. The inert atmosphere was also maintained during the heating up and cooling-down intervals. The furnace was preheated and maintained at the temperature of regeneration. Samples will be denoted as CiRi ( $\mathrm{Ci}$ being the cycles of saturation and $\mathrm{Ri}$ the number of regenerations), followed by a reference to the pollutant ( $p h$ for phenol and sa for salicylic acid). The effect of the temperature was also evaluated in the absence of the adsorbate. Therefore, the AC was initially pyrolysed in the absence of the adsorbate; the sample will be denoted as $Q N$.

Pyrolysis tests were also performed in a TGA92 thermogravimetric analyser from Setaram (TG) under an argon flow rate of $50 \mathrm{ml} \mathrm{min}$, at a heating rate of $5{ }^{\circ} \mathrm{C} \mathrm{min}{ }^{-1}$ up to a final temperature of $850{ }^{\circ} \mathrm{C}$. In this way, the evolution of the rate of mass loss with temperature for the samples studied was obtained.

\section{RESULTS AND DISCUSSION}

The influence of the thermal treatment on the porous structure of the selected AC in the absence of the adsorbate was studied. Table 1 shows the main textural parameters of the samples. The helium density of the AC decreased slightly after pyrolysis in the absence of the adsorbate (QN). This suggests that the thermal treatment itself modifies the structure of the AC, producing a denser material than the parent sample. Compared to the as-received sample, Q, a slight decrease in the adsorbed volume of the $\mathrm{N}_{2}$ isotherm was observed for $\mathrm{QN}$, especially at high relative pressures. The apparent BET surface area fell by $11 \%$ (cf. Table 1 ) and a significant decrease in the microporosity of the sample was also observed.

Figure 1 shows the DTG pyrolysis profiles of the parent sample, Q, after saturation with salicylic acid and phenol. It can be seen in this figure that the pyrolysis profiles of the adsorbates show significant differences. From these profiles the temperature range of thermal desorption can be estimated. In the case of the sample previously saturated with phenol, two peaks at 220 and $400{ }^{\circ} \mathrm{C}$ were observed, whereas only one peak at low temperature appeared in the case of the sample exhausted with salicylic acid. These results throw some light on the nature of the forces involved in the process of adsorption of the two compounds, suggesting that adsorption occurs via different pathways.

In the case of the samples exhausted with phenol, from the results presented in Figure 1 it can be deduced that the desorption process occurs in two distinct and successive steps. The first weight loss step is associated with the evolution of physisorbed phenol molecules that are trapped in the pore 
structure of the AC. This is followed by a second step, between 300 and $500{ }^{\circ} \mathrm{C}$, which corresponds to the evolution of the chemisorbed fraction, in the form of light gases and heavy products. Thus, in the case of phenol adsorption, pyrolysis features revealed two binding states, a physisorbed state, which desorbed at $220^{\circ} \mathrm{C}$, and a chemisorbed state, which desorbed at $400{ }^{\circ} \mathrm{C}$. This is in agreement with the results of other authors on the regeneration of activated carbons saturated with phenol [7, 21-23].

In contrast, the evolution profile of the sample saturated with salicylic acid shows a peak centred at around $260^{\circ} \mathrm{C}$, indicating that the desorption of salicylic acid occurs at low temperature, in only one step. This shows that the uptake of this compound proceeds via a single mechanism of adsorption. The low temperature peak of the salicylic acid pyrolysis profile indicates that this compound exhibits a physisorption feature.

In the case of phenol, higher temperatures are needed for its desorption. Consequently, it can be inferred that phenol is retained on the activated carbon by forces of a stronger nature than those involved in salicylic acid adsorption. This result corroborates the premise supported in previous studies that physisorption is the main mechanism of adsorption of salicylic acid on activated carbon [24, 25].

The $\mathrm{N}_{2}$ adsorption isotherms at $-196{ }^{\circ} \mathrm{C}$ of the samples after successive cycles of pyrolysis were all type I on the BDDT classification [26], which indicates that they are mainly microporous adsorbents (cf. Figure 2). The desorption isotherms were roughly reversible, which is indicative of a slight development of mesoporosity. The isotherms of the pyrolysed samples kept roughly the same shape as those of the as-received AC, pointing to a steady and relatively homogeneous destruction of the porosity. It is also worth noting that the slope of the $\mathrm{N}_{2}$ isotherms decreased substantially with the successive cycles of regeneration for both adsorbates. This trend, however, was more evident in the case of the samples previously saturated with phenol.

The corresponding parameters of the BET and the DR equations of the pyrolysed samples from the $\mathrm{N}_{2}$ adsorption isotherms are recorded in Table 1. It was found that the apparent BET surface area decreased with the number of regeneration cycles, this reduction being specially significant when the AC was saturated with phenol. After the first pyrolysis cycle for the AC exhausted with phenol, the BET area decreased by approximately $28 \%$, in comparison with Q. Consecutive of uptake/pyrolysis cycles led to a continuous and sharp fall of as much as $86 \%$ after six cycles. These results are proof that the adsorbate was only partially desorbed during pyrolysis. As a consequence of this partial compound removal, the porous structure of the sample seems to remain blocked and hence the apparent BET surface area is decreased. This decrease was also observed for the micropore volume, $\mathrm{W}_{\mathrm{o}}$. Concerning accessible pore width, L, calculated from the Stoeckli-Ballerini equation [27], it can be clearly seen that the microporosity broadens with the pyrolysis of exhausted activated carbons (cf. Table 1).

As opposed to the behaviour of phenol, textural changes are less important in the samples previously saturated with salicylic acid. After the first cycle $(Q C 1 R 1 \mathrm{~s} a)$, the diminution of the apparent BET 
surface area was $13 \%$, which is much lower than the $28 \%$ observed for the samples saturated with phenol. After 6 cycles, this value was reduced by up to $50 \%$. It is also significant that the microporosity of the samples widened after several cycles (QC6R6 sa), which is confirmed by the increase in $L$ values and the corresponding decrease in $E_{o}$ (cf. Table 1), this effect being more evident in the case of phenol.

Figure 3 shows the evolution of the micropore size distribution over successive pyrolysis cycles, in accordance with the Horvath-Kawazoe method [28], which was applied to the nitrogen adsorption isotherms. It can be observed that sample $Q$ presents one peak centred at around $0.6 \mathrm{~nm}$ and a shoulder at $0.7 \mathrm{~nm}$, which is an indicative of a narrow microporosity. For the saturation with phenol, the intensity of the peak at $0.6 \mathrm{~nm}$ decreases abruptly with the cycles, and almost disappears after 3 steps. The results also show that the higher the number of cycles, the wider the micropore size distribution. For saturation with salicylic acid, the decrease in the height of the maximum at $0.7 \mathrm{~nm}$ is more gradual, suggesting that the microporosity has widened to a lesser extent.

The adsorption isotherms of $\mathrm{CO}_{2}$ at $0{ }^{\circ} \mathrm{C}$ for the samples are presented in Figure 4 . The DubininRaduskevich [18] equation was also applied to the $\mathrm{CO}_{2}$ adsorption isotherms, 0.36 being used as the $\beta$ parameter [29]. The values of the textural parameters are presented in Table 2. It can be observed that the adsorption of $\mathrm{CO}_{2}$ decreases over the regeneration cycles for both adsorbates. In the case of phenol, the narrow micropore volume, $\mathrm{W}_{0}$, decreases steadily from $0.212 \mathrm{~cm}^{3} \mathrm{~g}^{-1}$ for $Q$ to 0.108 for QC6R6 ph (cf. Table 2). As discussed above, the accessible pore width, L, calculated from the $\mathrm{N}_{2}$ adsorption data shows a clear broadening of microporosity with the pyrolysis cycles (cf. Table 1). As the micropore width increases, the volume of $\mathrm{CO}_{2}$ diminishes, because the larger pores cannot be filled at the low relative pressures at which the adsorption of $\mathrm{CO}_{2}$ is measured. Consequently, the narrow microporosity $\left(\mathrm{W}_{\mathrm{o}}\right.$, evaluated from $\left.\mathrm{CO}_{2}\right)$ of the pyrolysed samples decreases.

The decrease in the $\mathrm{CO}_{2}$ adsorbed is more evident when the $\mathrm{AC}$ is saturated with phenol. This could be indicative of an obstruction of the fine microporous structure of the AC, which suggests that a fraction of the products formed from phenol thermal decomposition remain partially retained in the inner pores of the adsorbent after heating at $850{ }^{\circ} \mathrm{C}$, while salicylic acid is readily desorbed. These findings are in good agreement with the micropore size distribution obtained from the nitrogen adsorption isotherms shown in Figure 3.

A detailed view of the changes in porosity is presented in Figure 5, where the micropore and narrow micropore volumes -evaluated from $\mathrm{N}_{2}$ and $\mathrm{CO}_{2}$ adsorption data, respectively- are plotted vs. the pyrolysis cycles. In all cases, greater changes are observed in the samples exhausted with phenol; the pyrolysis of samples saturated with salicylic acid results in a better preservation of the porous structure of the activated carbons. Concerning narrow microporosity, a slow and gradual fall is observed due to the successive cycles of pyrolysis, while the evolution is sharper and more abrupt for microporosity. The fact that the narrow micropore volume also decreases with the pyrolysis cycles, evidences that adsorption not only takes place in the microporous pattern of the activated carbons but also, although 
to a lesser extent, in the narrow micropores. This slight reduction in narrow micropore volume suggests that desorption of both adsorbates is easier from the narrow micropores than when the adsorption takes place in pores larger than $0.7 \mathrm{~nm}$.

The progressive reduction of the microporosity of the pyrolysed samples points to an incomplete desorption of the compounds retained. As a result of the partial removal of the products deposited within the pore system of the activated carbons during pyrolysis, a gradual blocking of the porous structure occurs.

The extent of the products deposited within the pore system of the AC will depend on the nature of the forces involved in the process of adsorption of each compound. Although in both cases the porosity of the adsorbent is gradually altered during the regeneration cycles the induced changes are less pronounced when the carbon is previously saturated with salicylic acid.

Desorption of phenol at low temperature is most likely due to the evolution of the physisorbed fraction on the AC. At high temperatures, the chemisorbed fraction -whose bonds are of a high energyevolves. During the regeneration, the desorbed phenol decomposes due to the high temperature of the treatment, so that sub-products of the phenol decomposition remain inside the porous structure of the AC [30]. The carbonaceous residue deposited on the AC obstructs the porous structure of the adsorbent. Hence, the pores, although not effectively occupied by adsorbate, cannot be penetrated by nitrogen molecules and consequently there is a decrease in the apparent BET surface area and a widening of the microporosity.

On the other hand, the textural characteristics of the samples saturated with salicylic acid are preserved more effectively than those of the samples exhausted with phenol. This might be explained in terms of the weaker nature of the forces involved in the process of adsorption (compared to phenol uptake), as can be inferred from the pyrolysis profile. Desorption of salicylic acid proceeds in a single peak profile at low temperature, indicating that the forces are of a weaker nature than those related with phenol adsorption. This suggests that the desorption of the former compound proceeds more readily than the desorption of phenol.

Thus, it seems that fewer carbonaceous residues are deposited on the internal structure of the samples saturated with salicylic acid. Consequently, the decrease in surface area and the widening of microporosity occurs to a lesser extent than in the case of phenol (cf. Table 1-2).

In fact, the experimental data confirm the importance of the porous structure of the carbon material in the adsorption of this compound, as opposed to phenol adsorption. The adsorption of salicylic acid is thought to be related to the porous structure of the AC rather than to the surface chemistry. This being the case, desorption of this organic compound can be expected to occur more readily. Most of the salicylic acid is physically adsorbed, so that the forces involved in this process are of a weak nature. Consequently desorption occurs to a greater extent. This premise is corroborated by the textural characteristics of the pyrolysed samples and by the pyrolysis experiments (Figure 1) and is further 
confirmation that the adsorptive capacities for salicylic acid retention are greater after several regeneration cycles, as compared to phenol uptake.

The results for the loading capacity of the parent and the pyrolysed samples are presented in Table 3 . In general, a substantial decrease was observed after successive regeneration cycles. However, phenol and salicylic acid retention present different behaviours.

Interestingly, a slight increase in the uptake of both compounds was observed when the activated carbon was treated under the same pyrolysis conditions in absence of the adsorbate (QN sample). Thermal treatment of the parent activated carbon, Q, eliminates the oxygenated surface functional groups. Consequently, the $\pi$-electron density of the graphene layers of the activated carbons increases, as do the dispersive interactions between the phenol and the $\pi$-electron density of the carbon [31]. Accordingly, there is an increase in the chemisorption contribution to the overall loading capacity of phenol. On the other hand, previous findings have shown that changes in the surface chemistry of the AC do not alter the salicylic acid uptake [24, 25], so that the slight increase in this case could be due to cleaning effect at the entrance to the pores as a consequence of the thermal treatment on the carbon surface.

Phenol uptake decreased promptly with the pyrolysis cycles, compared to the adsorption capacity of the parent sample, $\mathrm{Q}$. The reduction in the adsorptive capacity rose from $30 \%$ after the second cycle to $83 \%$ after the sixth cycle. The almost negligible adsorptive capacities of the highly pyrolysed samples are most likely due to the lack of a solid porous structure in these samples. This decrease is in agreement with the partial desorption of phenol molecules that is suggested by the textural changes observed in the regenerated samples.

In contrast, the adsorptive capacities of the AC after several regeneration cycles were found to be greater in the case of salicylic acid retention, compared to phenol uptake. There is a steady decrease with the cycles of pyrolysis, as opposed to an abrupt reduction in the case of phenol. In particular, it should be pointed out that, after the sixth cycle, adsorptive capacity was reduced by $41 \%$ to $83 \%$ in the case of phenol uptake.

\section{CONCLUSIONS}

Consecutive cycles of pyrolysis of AC exhausted with phenol and salicylic acid generate substantial changes in the porous structure of the original AC. A shift of the micropore distribution toward wider pores was observed, together with a decrease in the apparent BET surface areas. This is attributed to the incomplete desorption of the adsorbates during pyrolysis.

The DTG pyrolysis profiles of the parent sample after saturation with salicylic acid and phenol indicate that the adsorption of these adsorbates occurs via different pathways. The results clearly show that phenol exhibits physisorption and chemisorption features. Decomposition of phenol under an inert atmosphere may give rise to the deposition of residues on the porous structure of the activated samples. This carbonaceous residue is not evolved during pyrolysis, causing the blockage of the 
porous lattice of the sample. Consequently, the adsorptive capacities for phenol retention after subsequent adsorption/pyrolysis cycles were found to decrease significantly.

In contrast, the DTG evolution profile of the sample saturated with salicylic acid, along with the minor textural changes induced in the pyrolysed samples confirms physisorption as the main mechanism of adsorption of salicylic acid on the activated carbon. The low temperature of salicylic acid desorption obtained in the pyrolysis profiles indicates that this compound is retained by forces of a weaker nature. Salicylic acid seems to be desorbed with greater facility than that of phenol, contributing to a greater preservation of the porous structure of the pyrolysed samples. Consequently, consecutive cycles give rise to higher adsorptive capacities. The results confirm that salicylic acid uptake depends on the texture of the activated carbon, rather than on the surface chemistry.

\section{ACKNOWLEDGEMENTS}

The authors thank the European Commission, the Spanish Ministry of Science and Technology (research Project 1FD 1997-400-CO2-01) and Química Farmacéutica Bayer for financial support. 


\section{REFERENCES}

[1] B. Ferrari, N. Paxeus, R.L. Guidice, A. Pollio, J. Garric, Ecotoxicology Environmental Safety 55 (2000) 359.

[2] D.W. Mazyck, F.S. Cannon, Carbon 38 (2000) 1785.

[3] G.M. Walker, L.R. Weatherley, Sep. Sci. Technol. 35 (2000) 1329.

[4] M. Gurrath, T. Kuretzky, H.P. Boehm, L.B. Okhlopkova, A.S. Lisitsyn, V.A. Likholobov, Carbon 38 (2000) 1241.

[5] K. Hadidi, D.R. Cohn, S. Vitale, L. Bromberg, J. Air Waste Manage. Assoc. 49 (1999) 225.

[6] D.M. Nevskaia, A. Santianes, V. Muñoz, A. Guerrero Ruiz, Carbon 37 (1999) 1065.

[7] C. Moreno-Castilla, J. Rivera-Utrilla, M.V. López-Ramos, F. Carrasco-Marín, Carbon 33 (1995) 845.

[8] R. Wang, S. Chang, J. Chem. Technol. Biotechnol 74 (1999) 647.

[9] S. Sircar, T.C. Golden, M.B. Rao, Carbon 34 (1996) 1.

[10] Roskill Information Services Ltd. The economics of activated carbon. Clapham Road. SW9 OJA, London, 1998.

[11] N.W. Brown, E.P.L. Roberts, A.A. Garforth, R.A.W. Dryfe, Electrochimica Acta 49 (2004) 3269.

[12] J.-L. Lim, M. Okada, Ultrasonics Sonochemistry (2004) in press

[13] C.O. Ania, J.B. Parra, J.A. Menendez, J.J. Pis, Carbon 42 (2004) 1383.

[14] F. Salvador, C. Sanchez Jiménez, Carbon 37 (1999) 577.

[15] M.A. Ferro-García, J. Rivera-Utrilla, I. Bautista-Toledo, C. Moreno-Castilla, J. Chem. Technol. Biotechnol. 67 (1996) 83.

[16] G. Bercic, A. Pintar, J. Levec, Ind. Eng. Chem. Res. 35 (1996) 4619.

[17] E. Sabio, M.L. Gonzalez-Marin, A. Ramiro, J. F. Gonzalez, J.M. Bruque, L. Labajos-Brocano, J.M. Encinar, J. Colloid Interface Science 242 (2001) 31.

[18] M.M. Dubinin, Progr. Surf. Membr. Sci 9 (1975) 10.

[19] J.F. Byrne, H. Marsh, Porosity in carbons; characterization and applications, Patrick JW, Edward Arnold, Great Britain, 1995.

[20] L. Cummings, R.S. Summers, J. Am. Water Works Association 86 (1994) 88.

[21] M.A. Ferro-Garcia, J.P. Joly, J. Rivera-Utrilla and C. Moreno-Castilla, Langmuir, 11 (1995) 2648.

[22] M.A. Ferro-Garcia, E. Utrera-Hidalgo, J. Rivera-Utrilla, C. Moreno-Castilla and J.P. Joly, Carbon 31 (1993) 857.

[23] P.M. Alvarez, F.J. Beltran, V. Gomez-Serrano, J. Jaramillo, E.M. Rodriguez, Water Research 38 (2004) 2155.

[24] C.O. Ania, J.B. Parra, J.J. Pis, Fuel Proc. Technol. 79 (2002) 265.

[25] C.O. Ania, J.B. Parra, J.J. Pis, Ads. Sci. Technol. (2004) (in press) 
[26] S. Brunauer, L.S. Deming, W.E. Deming, E. Teller, J. Am. Chem. Soc.62 (1940) 1723.

[27] F. Stoeckli, L. Ballerini, Fuel, 70 (1991) 557.

[28] G. Horvath, K. Kawazoe, J. Chem. Eng. Japan 16 (1983) 470.

[29] A. Guillot, F. Stoeckli, Carbon 39 (2001) 2059.

[30] S. Cooke, M.M. Labes, Carbon 32 (1994) 1055.

[31] A.P. Terzyk, J. Colloid Interface Science 268 (2003) 301. 
Table 1. Textural properties of the studied samples derived from densities measurements and $\mathrm{N}_{2}$ adsorption isotherms at $-196{ }^{\circ} \mathrm{C}$.

\begin{tabular}{|c|c|c|c|c|c|c|}
\hline & \multirow{2}{*}{$\begin{array}{l}\text { Helium density } \\
\qquad\left(\mathrm{g} \mathrm{cm}^{-3}\right)\end{array}$} & \multirow{2}{*}{$\begin{array}{c}S_{B E T} \\
\left(m^{2} g^{-1}\right)\end{array}$} & \multirow[b]{2}{*}{$C_{B E T}$} & \multicolumn{3}{|c|}{ DR method } \\
\hline & & & & $\begin{array}{c}W_{o} \\
\left(\mathrm{~cm}^{3} \mathrm{~g}^{-1}\right)\end{array}$ & $\begin{array}{c}E_{o} \\
\left(\mathrm{~kJ} \mathrm{~mol}^{-1}\right)\end{array}$ & $\begin{array}{c}L \\
(n m)\end{array}$ \\
\hline$Q$ & 2.18 & 1149 & 242 & 0.422 & 18.7 & 1.47 \\
\hline$Q N$ & 2.14 & 1022 & 353 & 0.378 & 19.7 & 1.29 \\
\hline QC1R1 ph & 2.11 & 822 & 302 & 0.299 & 20.1 & 1.24 \\
\hline QC3R3 ph & 2.04 & 340 & 130 & 0.115 & 18.3 & 1.56 \\
\hline QC6R6 ph & 2.04 & 162 & 88 & 0.052 & 17.7 & 1.71 \\
\hline QC1R1 sa & 2.18 & 995 & 260 & 0.364 & 19.2 & 1.38 \\
\hline QC3R3 sa & 2.15 & 868 & 260 & 0.316 & 19.5 & 1.33 \\
\hline QC6R6 sa & 2.10 & 594 & 161 & 0.213 & 18.1 & 1.61 \\
\hline
\end{tabular}


Table 2. Textural parameters of the studied samples derived from the Dubinin-Radushkevich equation applied to $\mathrm{CO}_{2}$ adsorption isotherms at $0^{\circ} \mathrm{C}$.

\begin{tabular}{lcccc}
\hline & $\begin{array}{c}\boldsymbol{W}_{\boldsymbol{o}} \\
\left(\mathbf{c m}^{\mathbf{3}} \mathbf{g}^{-1}\right)\end{array}$ & $\begin{array}{c}\boldsymbol{E}_{\boldsymbol{o}} \\
\left(\mathbf{k J ~ m o l}^{-\mathbf{1}}\right)\end{array}$ & $\begin{array}{c}\mathbf{L} \\
(\mathbf{n m})\end{array}$ & $\begin{array}{c}\boldsymbol{S}_{\boldsymbol{m i}} \\
\left(\boldsymbol{m}^{2} \boldsymbol{g}^{-1}\right)\end{array}$ \\
\hline $\boldsymbol{Q}$ & 0.212 & 27.00 & 0.69 & 611 \\
$\mathbf{Q N}$ & 0.212 & 27.15 & 0.69 & 612 \\
\hline QC1R1 $\mathbf{p h}$ & 0.174 & 27.99 & 0.65 & 534 \\
QC3R3 $\mathbf{p h}$ & 0.148 & 27.78 & 0.66 & 448 \\
QC6R6 ph & 0.108 & 26.91 & 0.70 & 309 \\
\hline QC1R1 sa & 0.191 & 27.33 & 0.68 & 563 \\
QC3R3 sa & 0.177 & 27.75 & 0.66 & 536 \\
QC6R6 sa & 0.150 & 28.08 & 0.65 & 464 \\
\hline
\end{tabular}


Table 3. Adsorptive capacities of the studied samples after several pyrolysis cycles.

\begin{tabular}{lcc}
\hline \multicolumn{3}{c}{ Adsorptive capacities $\mathbf{~} \mathbf{~ g ~ g}^{\mathbf{- 1}}$ ) } \\
\hline & ph & sa \\
\hline $\boldsymbol{Q}$ & 232 & 399 \\
QN & 285 & 418 \\
QC1R1 & 161 & 387 \\
QC2R2 & 113 & 384 \\
QC3R3 & 71 & 332 \\
QC4R4 & 55 & 292 \\
QC5R5 & 40 & 237 \\
QC6R6 & 32 & 216 \\
\hline
\end{tabular}


Figure 1.DTG pyrolysis profiles of the activated carbon exhausted with phenol and salicylic acid.

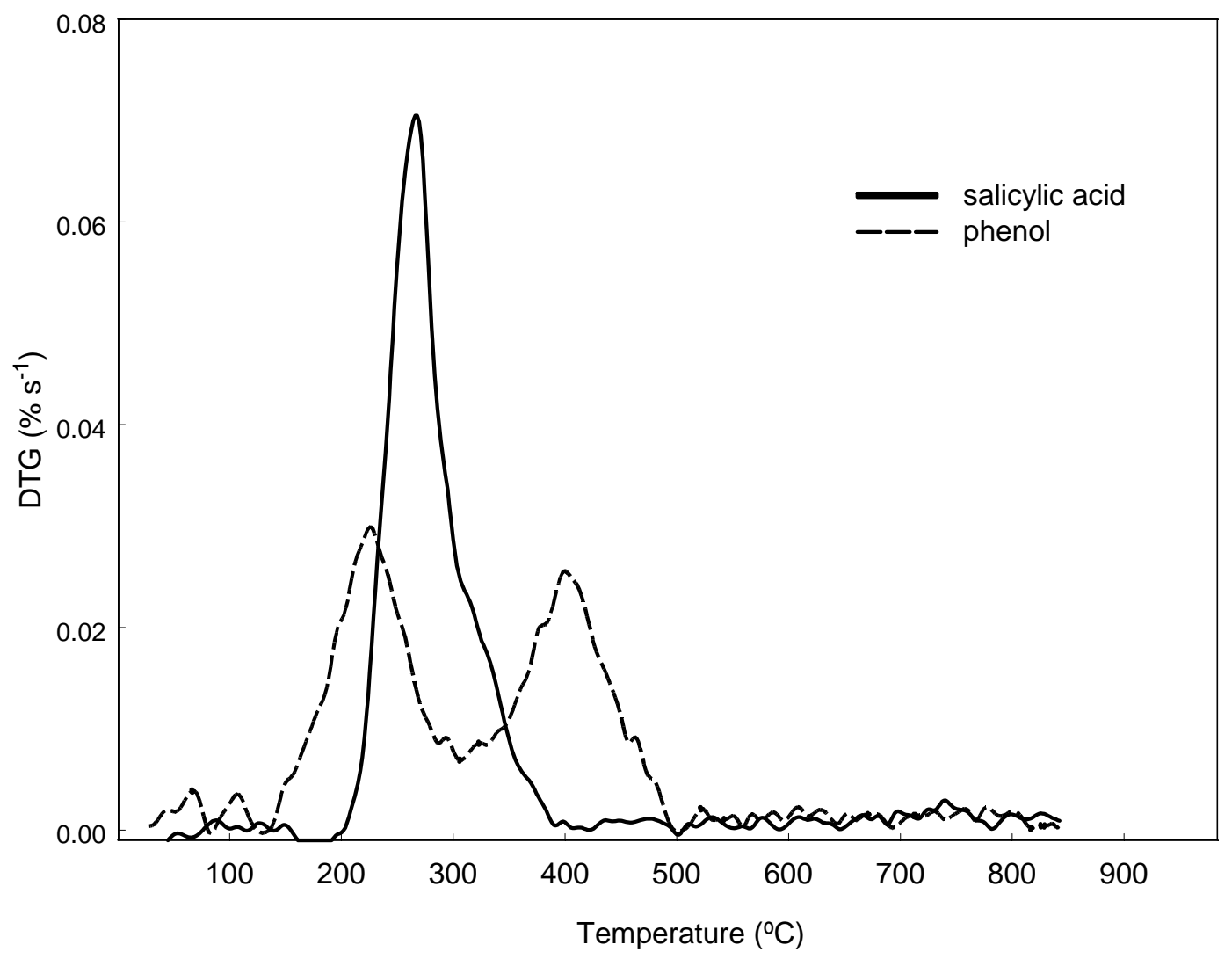


Figure 2. Nitrogen adsorption isotherms at $-196^{\circ} \mathrm{C}$ of the studied samples.
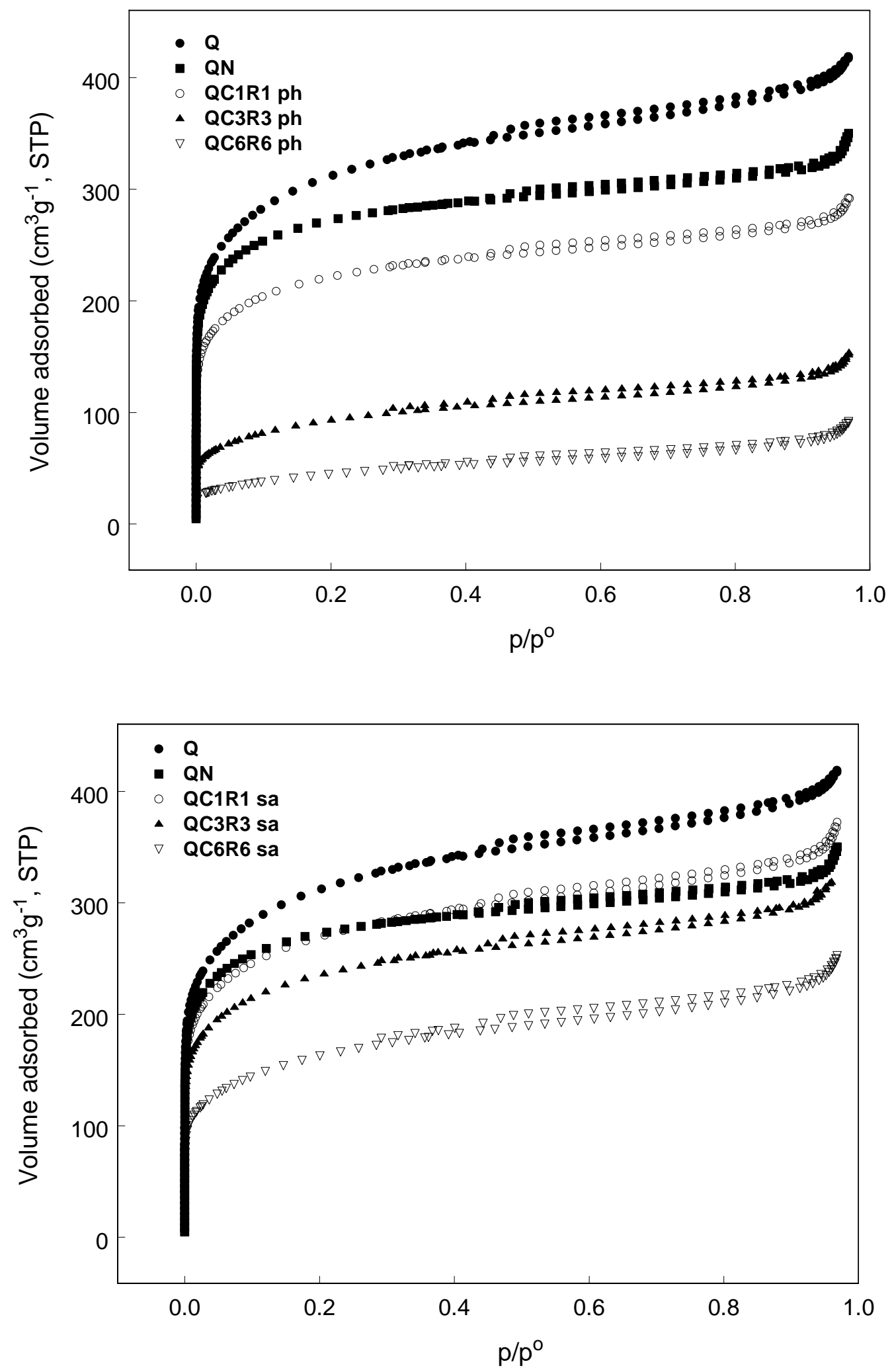
Figure 3. Micropore size distribution of the pyrolysed samples using the Horvath-Kawazoe method.
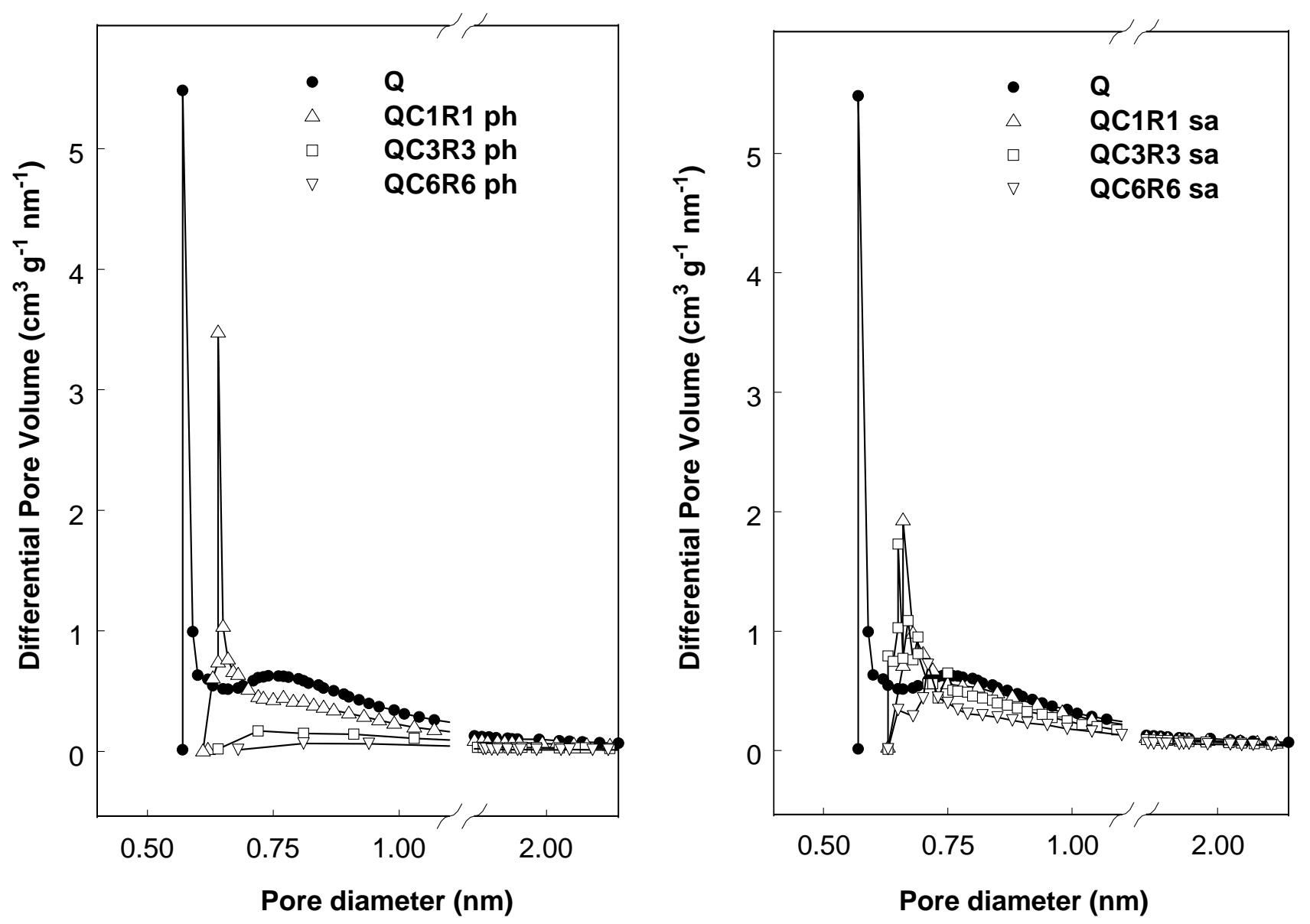
Figure 4. $\mathrm{CO}_{2}$ adsorption isotherms at $0^{\circ} \mathrm{C}$ of the studied samples.
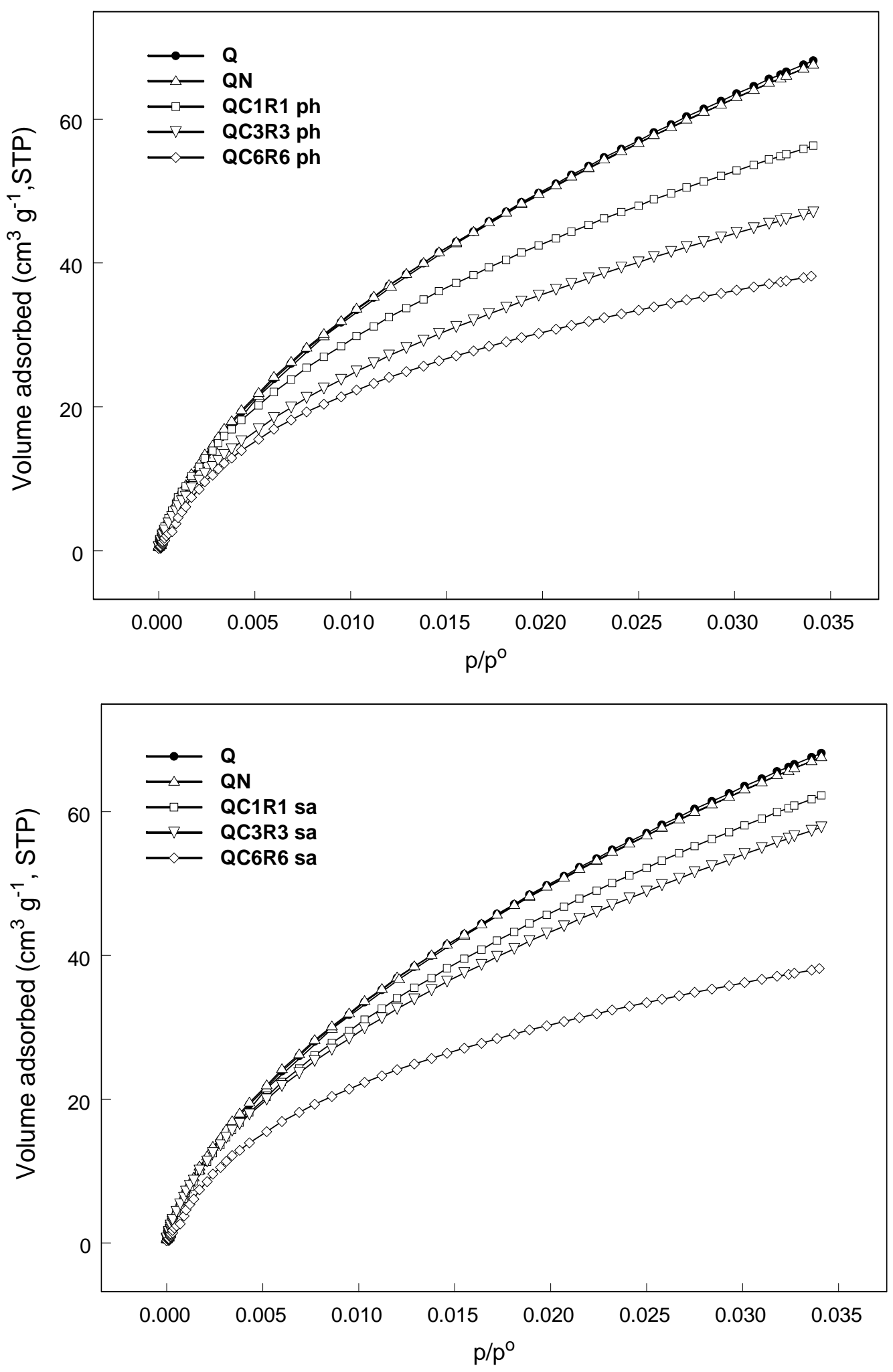
Figure 5. Variation in the micropore volume of the studied samples over successive pyrolysis cycles: solid symbols for saturation with phenol, and empty symbols for saturation with salicylic acid.

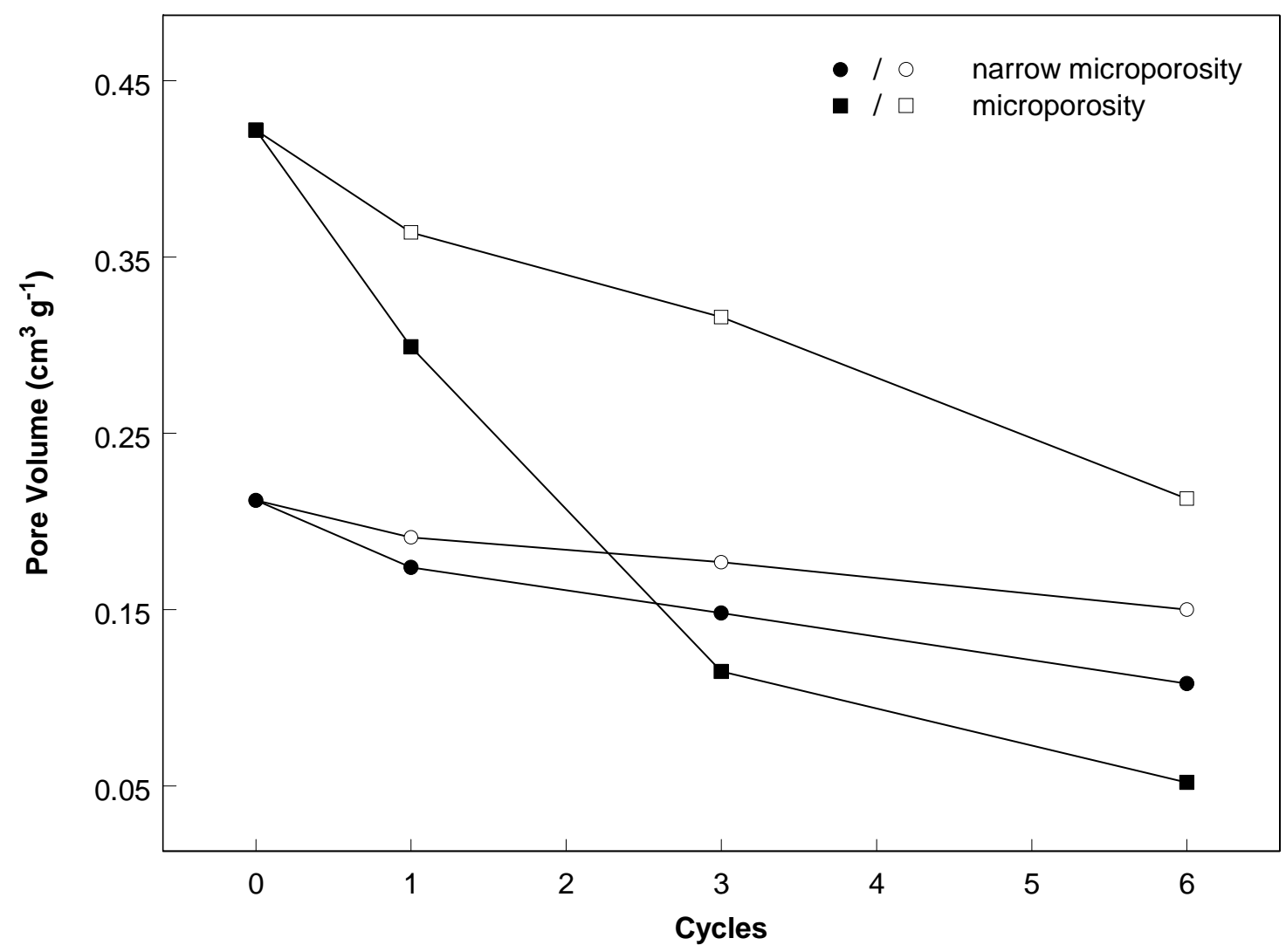

